\title{
Estimation of ferulic acid from selected plant materials by Spectrophotometry and High performance liquid chromatography
}

\author{
Saratchandran A. Divakaran* \\ Department of Botany, Sree Kerala Varma College, Thrissur - 680011 (Kerala), India \\ Anitha CT \\ Department of Botany, Sree Narayana College, Nattika, Thrissur - 680555 (Kerala), India \\ *Corresponding author. Email: saratcad@gmail.com
}

\section{Article Info}

https://doi.org/10.31018/

jans.v13i3.2732

Received: May 25, 2021

Revised: July 26, 2021

Accepted: August 1, 2021

\section{How to Cite}

Divakaran, S. A. and CT, Anitha (2021). Estimation of ferulic acid from selected plant materials by Spectrophotometry and High performance liquid chromatography. Journal of Applied and Natural Science, 13(2), 815 - 819. https://doi.org/10.31018/ jans.v13i3.2732

\begin{abstract}
Ferulic acid (FA) is an abundant phytophenolic compound present in plant cell wall. Ferulic acid possesses anticancer, antioxdant, and anti-aging properties. A simple, sensitive and reproducible spectrophotometric method has been exploited for quantitative estimation of ferulic acid from selected plant materials such as rice bran (Oryza sativa), wheat bran (Triticum aestivum) and bamboo shoot (Bambusa vulgaris). The blue coloured chromogen obtained after the Folin-Ciocalteu assay was measured at a wavelength of $718 \mathrm{~nm}$ for ferulic acid against the blank reagent. The chromogen obeyed linearity over the range of $1 \mu \mathrm{g} / \mathrm{ml}$ $8 \mu \mathrm{g} / \mathrm{ml}$. High-Performance Liquid Chromatography (HPLC) method was also developed for the estimation of ferulic acid from selected plant materials. In HPLC analysis, ferulic acid got eluted and the amount of FA was found to be higher in rice bran $(14.03 \mathrm{mg} / \mathrm{kg})$ compared to bamboo shoot $(1.92 \mathrm{mg} / \mathrm{kg})$ and wheat bran $(11.03 \mathrm{mg} / \mathrm{kg})$. The method can be used for the routine analysis of ferulic acid from various plant species and can be applied for nutritional and clinical investigations in a variety of samples.
\end{abstract}

Keywords: Bamboo shoot, Ferulic acid, Rice bran, Spectrophotometry, Wheat bran

\section{INTRODUCTION}

Antioxidants are compounds needed by most organisms, where they prevent oxidative damage caused by free radicals. The formation of free radicals causes the development of various diseases like cancer, cardiovascular diseases and cataracts in humans (Zhang et al., 2007). The antioxidant activities of plants have been mainly due to their phenolic content, which is one class of natural antioxidants (Castaneda et al., 2009). Thus, plants containing a high-level of phenolic acids considered a source of potent natural antioxidants (Ranusova et al., 2021). Ferulic acid (FA), together with dihydroferulic acid, could be a component of lignocelluloses, confers plasma membrane rigidity by cross linking lignin and polysaccharides. It is commonly found in seeds of plants like rice, wheat and oats (Buranov and Mazza, 2009). Ferulic acid will be easily absorbed by the body and stays within the blood longer than the other antioxidant, even longer than vitamin C. Thus FA can be considered as an important antioxidant and commonly used in nutrition purposes and food supplements (Silva and Batista, 2017).

Ferulic acid is found in many vegetable sources and occurs in particularly high concentration in popcorn and bamboo shoots. As an antioxidant, FA plays a major role in the body's defence against carcinogenesis by inhibiting the formation of $\mathrm{N}$-nitroso compounds (Kuenzig et al., 1984; Lee et al., 2009; Aarabi et al., 2016). Ferulic acid possesses anticancer, antioxidant, and anti-aging potentials and can decrease blood glucose levels. Like other phenolic compounds, FA showed radioprotective abilities and reduced ionizing radiation-induced damages to DNA and membranes in biological systems (Roginsky \& Lissi, 2005; Divakaran et al., 2013; Kumar and Goel, 2019).

Therefore, we exploited a simple, repeatable, sensitive and cost-effective VIS Spectrophotometric method for the quantification and determination of FA from various plant materials. Folin-Ciocalteu assay is used for the quantification of phenolic acid in the presence of alkali (15\% sodium carbonate). High-Performance Liquid 
Chromatography (HPLC) method is considered to be as an appropriate method for estimation of chemical constituents from plant materials. Therefore, HPLC analysis has also been used for the quantitative determination of ferulic acid.

\section{MATERIALS AND METHODS}

\section{Instruments}

Soxhlet apparatus, VIS spectrophotometer (Systronics), HPLC (Agilent Technologies 1200 Infinity Series ) were used.

\section{Chemicals}

AR grade chemicals such as ethyl acetate, Folin - Ciocalteu reagent and Sodium carbonate were obtained from Nice chemicals. Double distilled water was obtained after purification. Ferulic acid (FA) (Fig. 1) of $98 \%$ purity was purchased from NICE.

\section{Plant materials}

Plant materials selected such as rice bran (Oryza sativa), wheat bran (Triticum aestivum) and Bamboo shoot (Bambusa vulgaris) were collected from homestead region. Rice bran and wheat bran as whole and young bamboo shoot tip were dried, powdered with the help of blender and kept in sealed containers for future use.

\section{Folin-Ciocalteu assay}

Folin-Ciocalteu assay is based on of oxidationreduction reaction, containing molybdates, tungstates as the main components of the reagent. This assay is a commonly used method for the quantification of phenolic acids in samples. The phenolic compounds reduces the heteropolyphosphotungstates-molybdates into a blue coloured chromogen. The reaction is carried out only under basic conditions in the presence of washing soda solution. The Phenolate anion formed from phenolic compound reduces Folin-Ciocalteu reagent to form the blue coloured substance. Spectrophotometer can be used to measure the colour intensity of blue chromogen ( Jadhav et al., 2012).

\section{Standard solution of FA preparation (Stock)}

The stock solution of FA $(1 \mathrm{mg} / \mathrm{ml})$ was prepared by dissolving $10 \mathrm{mg} F A$ in ethyl acetate, final volume was made up to $10 \mathrm{ml}$ with ethyl acetate in volumetric flask. From this stock, $1 \mathrm{ml}$ was taken out and added to $10 \mathrm{ml}$ volumetric flask, and the volume was adjusted to $10 \mathrm{ml}$ by adding double distilled water to get $100 \mu \mathrm{g} / \mathrm{ml}$ concentration. This solution was used for further analysis for making calibration curve.

\section{Calibration curve of FA}

From the stock solution $(100 \mu \mathrm{g} / \mathrm{ml})$ of $\mathrm{FA}, 0.1 \mathrm{ml}$ to 0.8 $\mathrm{ml}$ aliquots were added to a volumetric flask $(10 \mathrm{ml})$. To this flask, $2 \mathrm{ml}$ of sodium carbonate solution (15\%) and Folin-Ciocalteu reagent $(0.5 \mathrm{ml})$ diluted with double distilled water (1:2 ratio) were added. The final volume was added with double distilled water to get a solution ranging in concentration from $1 \mu \mathrm{g} / \mathrm{ml}-8 \mu \mathrm{g} / \mathrm{ml}$ of FA. The mixture showed maximum absorption at $718 \mathrm{~nm}$ when calculated against the blank solution. The absorbance of all solutions can be measured, and a calibration curve was plotted.

\section{Preparation of ethyl acetate extract of plant materials} Accurately weighed $10 \mathrm{~g}$ of maize, wheat bran, rice bran, and bamboo shoot was extracted separately with $100 \mathrm{ml}$ of ethyl acetate with the help of the Soxhlet apparatus. The resulting crude extract was used for further analysis.

\section{Preparation of sample solution}

The extract solution $(1 \mathrm{ml})$ was added to the volumetric flask $(10 \mathrm{ml})$. To the flask, Folin - Ciocalteu reagent $(0.5$ $\mathrm{ml})$ diluted with double distilled water (1:2 ratio) and 2 $\mathrm{ml}$ sodium carbonate solution (15\%) was added, the final volume was made up to $10 \mathrm{ml}$ with double distilled water. Absorbance was measured at $718 \mathrm{~nm}$ with a Spectrophotometer.

\section{Validation of the proposed method: Linearity}

The linearity was determined by constructing the calibration curve and evaluating it by linear least square regression analysis.

\section{Chromatography}

Column : C18 4.6×250mm $\times 5 \mu \mathrm{m}$

Flow rate $: 1.0 \mathrm{~mL} /$ Minute

Inj.Volume $: 20 \mu \mathrm{L}$

Wave length $: 319 \mathrm{~nm}$

Run time : 10 minute

Column temperature: $30^{\circ} \mathrm{C}$

Mobile phase: $5 \%$ Glacial Acetic acid in HPLC water : Acetonitrile ( 80:20)

\section{Standard preparation}

Ferulic acid Stock solution of 1000ppm was prepared in Methanol. From this, working standard of 2.5, 5, 10, 15, $20 \mathrm{ppm}$ were prepared by serial dilution of the stock solution with methanol.<smiles>COc1cc(/C=C/C(=O)O)ccc1O</smiles>

Fig. 1. Structure of ferulic acid. 
Divakaran, S. A. and CT, Anitha / J. Appl. \& Nat. Sci. 13(3), 815 - 819 (2021)

\section{Sample preparation}

The ethyl acetate extract of plant samples were concentrated, filtered with $0.45 \mu \mathrm{m}$ disposable filter, $20 \mu \mathrm{L}$ samples were injected to the HPLC system for the analysis.

\section{RESULTS AND DISCUSSION}

Ferulic acid is a strong scavenger of free radicals and it has been accepted as a food additive to prevent lipid peroxidation. The selected plant materials such as rice bran, wheat bran, bamboo shoot are recognized in different systems of traditional medicine for the treatment of various diseases (Kumar and Pruthi, 2014). The mixture of ferulic acid along with Folin Ciocalteu reagent in an alkaline medium yielded a maximum absorbance at $718 \mathrm{~nm}$. A linear relationship was obtained when a graph was plotted for concentration v/s absorbance within the concentration range of $1 \mu \mathrm{g} / \mathrm{ml}-8 \mu \mathrm{g} / \mathrm{ml}$ with a correlation coefficient value $\mathrm{r} 2=0.988$ and therefore, the rectilinear regression equation was $y=0.094 x$ -0.001 (Table. 1 ).

The various samples used for the studies yielded different concentrations of FA, calculated by using the standard graph (Fig. 2). The bamboo shoot sample used for the study contained $1.7 \mu \mathrm{g} / \mathrm{ml}$ of $\mathrm{FA}$, the wheat bran sample contains $7.3 \mu \mathrm{g} / \mathrm{ml}$, and the rice bran sample yielded a maximum amount as $8 \mu \mathrm{g} / \mathrm{ml}$ (Table 2 ).

\section{Chromatographic studies}

In the HPLC analysis, Ferulic acid got eluted at 6.82 min (Fig. 4) and the peak for the same was found to be at 6.794 in the bamboo shoot sample (Fig. 5), 6.804 for the wheat bran sample (Fig. 6) and 6.791 for rice bran sample (Fig. 7) under the conditions of detection at 319 $\mathrm{nm}$ and temperature $30^{\circ} \mathrm{C}$. The amount of ferulic acid in bamboo shoot, wheat bran and rice bran was found to be $1.92 \mathrm{mg} / \mathrm{kg}, 11.03 \mathrm{mg} / \mathrm{kg}$ and $14.03 \mathrm{mg} / \mathrm{kg}$, respectively, as calculated from the calibration curve of FA (Fig.3). The present study showed that rice bran yielded a higher amount of FA than bamboo shoot and wheat bran. Recent studies also unveiled the fact that rice bran is a rich source of antioxidant molecules such

Table 1. Regression analysis.

\begin{tabular}{ll}
\hline Regression equation & $\mathrm{y}=0.094 \mathrm{x}-0.001$ \\
Range & $1 \mu \mathrm{g} / \mathrm{ml}-8 \mu \mathrm{g} / \mathrm{ml}$ \\
Co-relation coefficient $\mathrm{r} 2$ & 0.988 \\
Slope m & 0.094 \\
$\mathrm{y}$-intercept & 0.001 \\
\hline
\end{tabular}

Table 2. Concentration of FA from various plant samples.

\begin{tabular}{ll}
\hline Sample & Unknown yield $(\mu \mathrm{g} / \mathrm{ml})$ \\
\hline Bamboo shoot & 1.7 \\
Wheat bran & 7.3 \\
Rice bran & 8.0
\end{tabular}

as y-oryzanol and ferulic acid (Arumsari et al., 2019; Tam et al., 2021).

The extraction of Ferulic acid has been found much attention nowadays because it exhibits a wide variety of biological activities, including antimicrobial, antiinflammatory, anti-thrombosis, anticancer, and antioxidant activities. However, the extraction procedure of phenolic acids from biomass is very complicated and proper methodology is yet to be developed (ZavalaLopez and Garcia-Lara, 2017; Zhong et al., 2019).

The extraction and purification of phenolic acid viz. ferulic acid from rice bran and orange peels by solvent extraction method was studied by Gogoi et al. (2017). One of the major drawbacks of this procedure is its requirement for large quantities of different solvents and chemicals, which generates a significant quantity of toxic solvent waste (Acosta-Estrada et al., 2014). Ideia et al. (2020) reported the use of autoclave to perform alkaline hydrolysis and partial purification by adsorption on a synthetic resin to obtain ferulic acid from brewer's spent grain. The procedure is additionally very time consuming, making the handling of several samples without delay a challenging task.

In the present study, the estimation of phenolic acid viz. ferulic acid from rice bran, wheat bran and bamboo shoot by spectrophotometric method and the HPLC technique seems to be simple, sensitive, reproducible

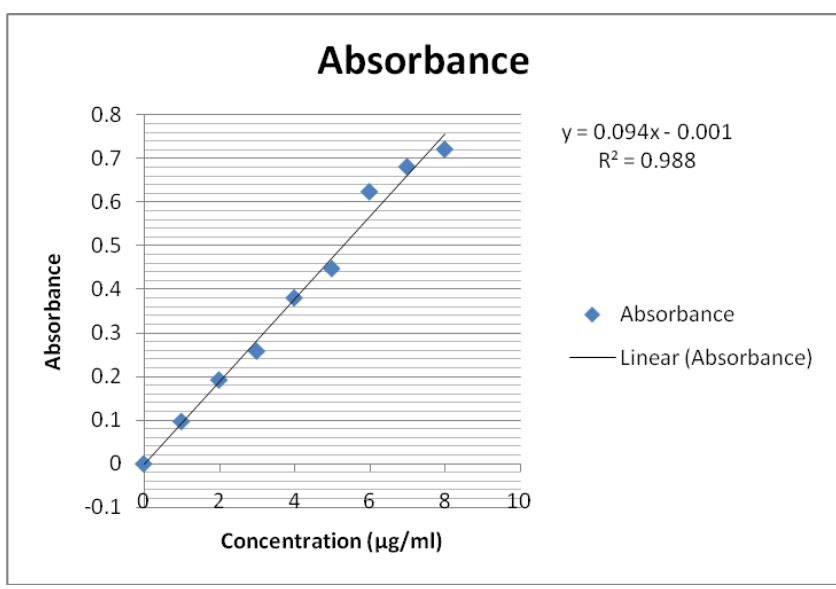

Fig. 2. Calibration curve of ferulic acid.

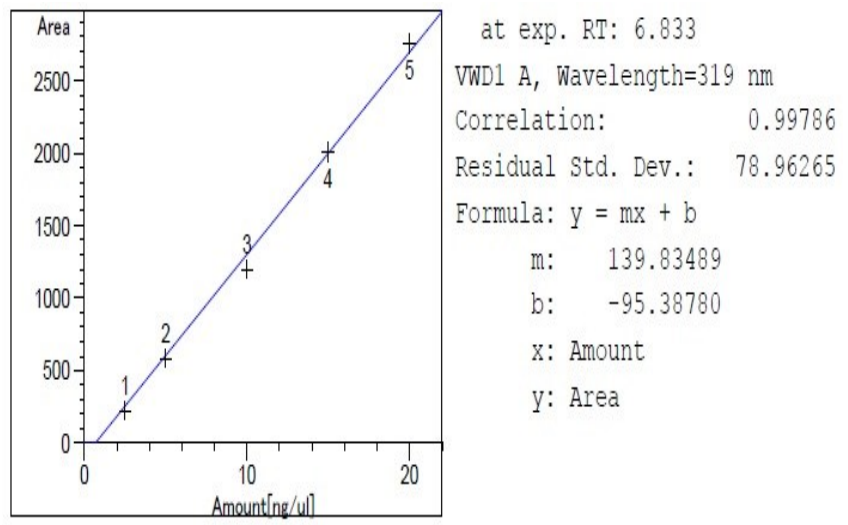

Fig. 3. Calibration curve of ferulic acid. 


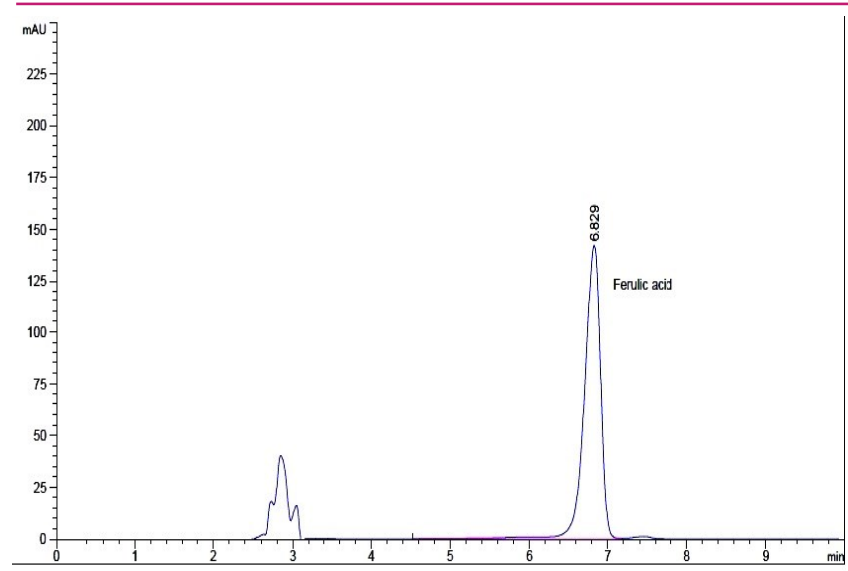

Fig. 4. HPLC chromatogram of standard ferulic acid.

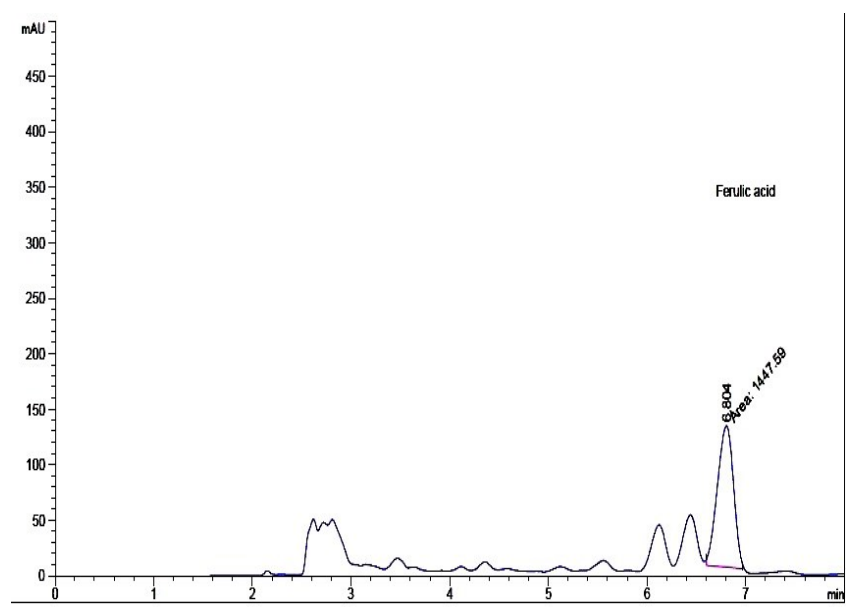

Fig. 6. HPLC chromatogram of ethyl acetate extract of wheat bran.

with minimum sample quantity, solvent and extraction time compared to methods proposed by Gogoi et al. (2017) and Ideia et al. (2020). The result obtained from the quantitative estimation of FA by Spectrophotometry and HPLC shows a parallel relationship. The chromatogram developed from HPLC also explains the isolation of ferulic acid with minimum impurities; hence can be recommended as a precise technique for the estimation of ferulic acid from plant samples.

\section{Conclusion}

A simple, sensitive and reproducible VISSpectrophotometric method has been exploited to estimate and quantify ferulic acid in various plant materials like bamboo shoots, rice bran and wheat bran etc., using Folin Ciocalteu reagent in the presence of an alkaline medium. The method can be employed for the routine analysis of ferulic acid from the various plant species. Moreover, they can prove to be helpful for nutritional and clinical investigations of ferulic acid levels in a variety of samples. The method for estimating ferulic acid in bamboo shoots, rice bran and wheat bran by

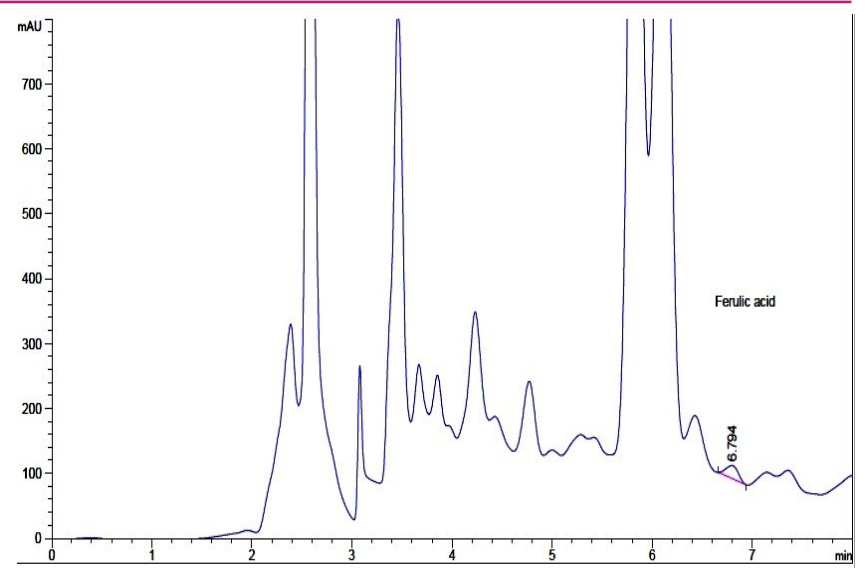

Fig. 5. HPLC chromatogram of ethyl acetate extract of bamboo shoot.

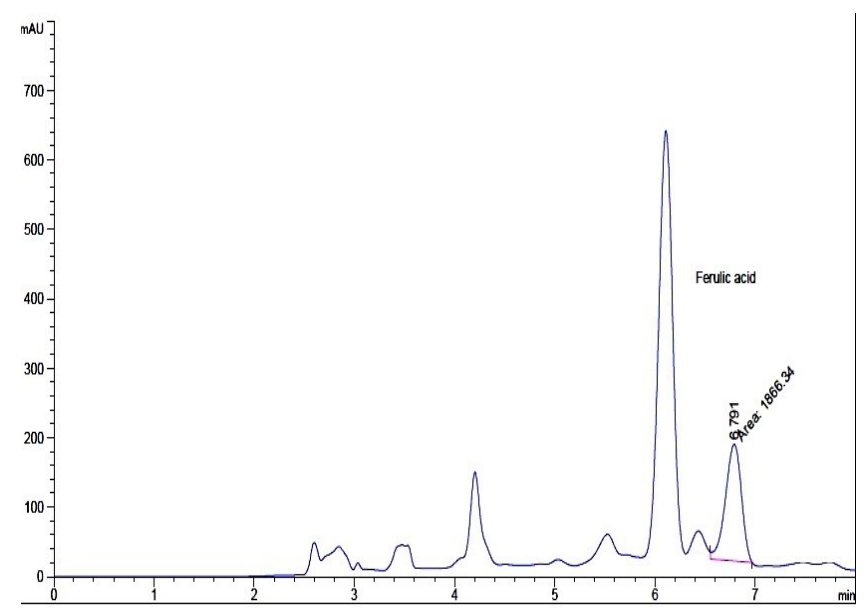

Fig.7. HPLC chromatogram of ethyl acetate extract of rice bran.

HPLC is accurate, precise and reproducible.

\section{ACKNOWLEDGEMENTS}

The authors express their gratitude to Sree Narayana College, Nattika, Thrissur, Kerala, India for the support given to Anitha CT and Saratchandran A Divakaran.

\section{Conflict of interest}

The authors declare that they have no conflict of interest.

\section{REFERENCES}

1. Aarabi, A., Honarvar, M., Mizani, M., Faghihian, H. \& Gerami, A. (2016). Extraction and purification of ferulic acid as an antioxidant from sugar beet pulp by alkaline hydrolysis. Italian Journal of Food Science, 28(3), 362375. doi https://doi.org/10.14674/1120-1770/ijfs.v143

2. Acosta-Estrada , B.A., Gutiérrez-Uribe, J.A. \& SernaSaldívar, S.O. (2014). Bound phenolics in foods, a review. Food Chemistry, 152, 46-55. doi: 10.1016/j.foodc hem.2013.11.093

3. Arumsari, A.G., Nugrahani, R. A. \& Hendrawati, T. Y. (2019). The extraction of ferulic acid from the phenolic 
fraction from rice bran oil using ultrasonic methods and analysis of antioxidant effectiveness. Advances in Health Sciences Research, 15, 37-39.

4. Buranov, A.U \& Mazza, G. (2009). Extraction and purification of ferulic acid from flax shives, wheat and corn bran by alkaline hydrolysis and pressurised solvents. Food Chemistry,115(4), 1542-1548. doi: 10.1016/j.foodchem.20 09.01.059

5. Castaneda, A., Hernandez, D., Hernandez, E., Rodríguez, J.A. \& Galan, C.A. (2009). Chemical studies of anthocyanins: a review. Food Chemistry, 113, 859-871. doi:10.1016/j.foodchem.2008.09.001

6. Divakaran, S.A., Hema, P.S., Nair, M.S. \& Nair, C.K.K (2013). Antioxidant capacity and radioprotective properties of the flavonoids galangin and kaempferide isolated from Alpinia galanga $L$. (Zingiberaceae) against radiation induced cellular DNA damage. International Journal of Radiation Research, 11(2), 81-89.

7. Gogoi, P., Gogoi, A., Rajbangshi, C., Bhuyan, P. \& Bhuyan, B.K. (2017). Extraction, purification and spectroscopic characterization of ferulic acid by alkaline hydrolysis from brans of Assam, India. Imperial Journal of Interdisciplinary Research, 3(1), 358-361.

8. Ideia, P., Sousa-Ferreira, I \& Castilho, P.C. (2020). A novel and simpler alkaline hydrolysis methodology for extraction of ferulic acid from brewer's spent grain and its (partial) purification through adsorption in a synthetic resin. Foods, 9 (5), 600. doi:10.3390/foods 9050600.

9. Jadhav, A.P., Kareparamban, J.A., Nikam, P.H. \& Kadam, V.J. (2012). Spectrophotometric estimation of ferulic acid from Ferula asafoetida by Folin - Ciocalteu's Reagent. Der Pharmacia Sinica, 3 (6), 680-684.

10. Kuenzig, W., Chau, J., Norkus, E., Holowaschenko, H., Newmark, H., Mergens, W. \& Conney, A.H. (1984). Caffeic and ferulic acid as blockers of nitrosamine formation. Carcinogenesis, 5(3), 309-313. doi: 10.1093/ carcin/5.3.309

11. Kumar, N. \& Goel, N. (2019). Phenolic acids: Natural versatile molecules with promisingtherapeutic applications. Biotechnology Reports, 24, e00370. doi: 10.1016/ j.btre.2019.e00370
12. Kumar, N. \& Pruthi, V. (2014). Potential applications of ferulic acid from natural sources. Biotechnology Reports, 4, 86-93. doi: 10.1016/j.btre.2014.09.002.

13. Lee, Y., Yuk, D., Lee, J., Lee, S., Ha, T., Oh, K., Yun, Y. \& Hong, J. (2009). Epigallocatechin-3-gallate prevents lipopolysaccharide-induced elevation of $\beta$-amyloid generation and memory deficiency. Brain Research, 1250, 164-174. doi: 10.1016/j.brainres.2008.10.012.

14. Ranusova, P., Matušíková, I \& Nemecek, P. (2021). Optimization of plant extract purification procedure for rapid screening analysis of sixteen phenolics by liquid chromatography. Separations, 8, 13. https://doi.org/10.3390/sep arations 8020013.

15. Roginsky, V. \& Lissi, E.A. (2005). Review of methods to determine chain-breaking antioxidant activity in food. Food Chemistry, 92(2), 235-254. doi:10.1016/j.foodchem.200 4.08.004

16. Silva, E. \& Batista. R. (2017). Ferulic acid and naturally occurring compounds bearing a feruloyl moiety: A review on their structures, occurrence, and potential health benefits. Comprehensive Reviews in Food Science and Food Safety, 16, 580-616. doi: 10.1111/1541-4337.12266.

17. Tam, L.T., Ha, N.C. \& Thom, L.T. (2021). Ferulic acid extracted from rice bran as a growth promoter for the microalga Nannochloropsis oculata. Journal of Applied Phycology, 33, 37-45. https://doi.org/10.1007/s10811-020-02 166-5

18. Zavala-Lopez, M. \& Garcia $\square$ Lara, S. (2017). An improved microscale method for extraction of phenolic acids from maize. Plant Methods, 13, 81. doi 10.1186/s13007-0170235-x

19. Zhang, Y.T., Xu, M.T., Du, M. \& Zhou, F.M. (2007). Comparative studies of the interaction between ferulic acid and bovine serum albumin by ACE and surface plasmon resonance. Electrophoresis, 28(11), 1839-1845. doi: 10.1002/ elps. 200700025

20. Zhong, L., Yuan, Z., Rong, L., Zhang, Y., Xiong, G., Liu, Y. \& Li, C. (2019). Extraction and Characterization of Phenolic Compounds in Dendranthema indicum var. aromaticum Flower. Scientific Reports, 9,7745. doi:10.1038/ s41598-019-44102-9 